\section{COMPETÊNCIA EM INFORMAÇÃO NO APOIO À GESTÃO DO CONHECIMENTO}

\author{
Heloá Cristina Oliveira Del Massa* \\ Ieda Pelogia Martins Damian* \\ Marta Lígia Pomim Valentim ${ }^{* * *}$
}

RESUMO

Palavras-Chaves: Gestão do Conhecimento. Competência em Informação. Fatores

Em um contexto de crescente valorização da informação e do conhecimento, o Século $X X I$ tem se evidenciado como reformulador de políticas institucionais, potencializando o capital humano para gerar inovação e obter vantagem competitiva. No entanto, as iniciativas voltadas à aplicação de uma gestão que, realmente possa trabalhar o capital humano em sua potencialidade são poucas. Os fatores críticos de sucesso são elementos relevantes que fazem parte da gestão do conhecimento e, como tal, devem ser fortemente monitorados. Os fatores críticos de sucesso podem abranger desde a comunicação, tecnologia, pessoas, processos até aspectos de liderança. Nesse cenário, a competência em informação enfatiza a perspectiva de que o sujeito organizacional seja capaz de utilizar a informação de maneira crítica, reflexiva, criativa, autônoma e ética em diferentes situações. $O$ uso da informação consistente e confiável para a construção de conhecimento organizacional é essencial, entretanto, questiona-se: os sujeitos organizacionais são competentes no uso da informação? Os sujeitos organizacionais conhecem as próprias necessidades informacionais? A partir de uma revisão bibliográfica, este artigo enfatiza a necessidade de se desenvolver a gestão do conhecimento alinhada a competência em informação. Nesse intuito, identificou-se as similaridades entre a Colnfo e os FCS, a fim de propor contribuições para a gestão do conhecimento obter efetividade de fato. Como resultado apresentase os principais fatores críticos de sucesso inter-relacionados aos principais padrões de desenvolvimento/aprimoramento da competência em informação, evidenciando as similaridades, bem como expondo a necessidade de valorização do uso competente da informação para a geração de conhecimento.

\section{Críticos de Sucesso. Padrões da Competência em Informação.}

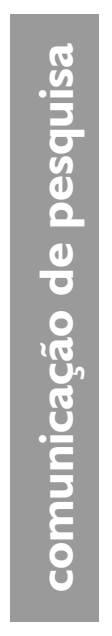

\footnotetext{
* Mestre em Ciência da Informação pela Universidade Estadual Paulista Júlio de Mesquita Filho, UNESP, Brasil. Doutoranda no Programa de Pós-Graduação em Ciência da Informação da Universidade Estadual Paulista Júlio de Mesquita Filho, Brasil. Membro do Grupo de Pesquisa CNPq Informação, Conhecimento e Inteligência Organizacional.

E-mail: heloaoliveira.biblio@gmail.com.

* Doutora em Administração de organizações pela Universidade de São Paulo, Brasil. Professora no curso de graduação em Ciência da Informação e Documentação da Universidade de São Paulo, Brasil. Docente no Programa de Pós-Graduação em Ciência da Informação da Universidade Estadual Paulista Júlio de Mesquita Filho, Brasil.

E-mail: ieda.martins@bol.com.br.

*** Doutora em Ciências da Comunicação pela Universidade de São Paulo, Brasil. Pós-Doutorado pela Universidad de Salamanca, Espanha. Livre Docente em Informação, Conhecimento e Inteligência Organizacional pela Universidade Estadual Paulista Júlio de Mesquita FiIho, Brasil. Líder do Grupo de Pesquisa $\mathrm{CNPq}$ Informação, Conhecimento e Inteligência Organizacional. Bolsista de Produtividade CNPq.

E-mail: valentim@valentim.pro.br.
}

\section{INTRODUÇÃO}

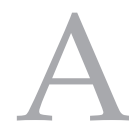

Gestão do Conhecimento (GC), seja em âmbitos privado ou público, propicia que planejamentos e tomadas de decisões sejam elaborados e alicerçados em análises e perspectivas lógicas e consistentes, resultando em uma atuação assertiva mesmo em cenários econômicos e/ou políticos inconstantes.
Fatores de risco são analisados, mapeamentos são executados, contextos internos e externos à organização são monitorados, entre outras práticas que visam obter um diagnóstico preciso da realidade em que as organizações estão inseridas. Além disso, é necessário alinhar todos esses aspectos à missão, visão, objetivos e metas organizacionais que, por sua vez, possibilitam o estabelecimento de práticas que visam a melhoria 
de todos os processos organizacionais, buscando atingir a maturidade necessária para manter a qualidade e gerar diferenciais competitivos.

A aplicação de programas de GC é consequência de uma boa gestão organizacional. Os benefícios de sua aplicação transcendem resultados imediatos, pois quando executada de maneira adequada, proporciona qualidade, criatividade e inovação de modo contínuo.

Em um contexto de crescente valorização da informação e do conhecimento, o Século XXI tem se evidenciado como reformulador de políticas institucionais, potencializando o capital humano para gerar inovação e obter vantagem competitiva. No entanto, as iniciativas voltadas à aplicação de uma gestão que, realmente possa trabalhar o capital humano em sua potencialidade são poucas. Essa dificuldade está relacionada apenas a maneira de aplicação ou também está relacionada as incapacidades do próprio fator humano?

Os Fatores Críticos de Sucesso (FCS) são elementos relevantes que fazem parte da gestão do conhecimento e, como tal, devem ser fortemente monitorados. Os fatores críticos de sucesso podem abranger desde a comunicação, tecnologia, pessoas, processos até aspectos de liderança. Nesse cenário, a competência em informação (CoInfo) enfatiza a perspectiva de que o sujeito organizacional seja capaz de utilizar a informação de maneira crítica, reflexiva, criativa, autônoma e ética em diferentes situações.

Em um contexto simplista: há a constante necessidade de se utilizar a informação para a construção de conhecimento, assim a informação se constitui em insumo para a geração de conhecimento. $\mathrm{O}$ uso da informação consistente e confiável para a construção de conhecimento organizacional é essencial, entretanto, questiona-se: os sujeitos organizacionais são competentes no uso da informação? Os sujeitos organizacionais conhecem as próprias necessidades informacionais?

A partir de uma revisão bibliográfica, este artigo enfatiza a necessidade de se desenvolver a gestão do conhecimento alinhada a competência em informação. Nesse intuito, identificouse as similaridades entre a CoInfo e os FCS, a fim de propor contribuições para a gestão do conhecimento obter efetividade de fato.

\section{GESTÃO DO CONHECIMENTO (GC)}

Autores consagrados da área de GC, Nonaka e Takeuchi (1997, p.79) explicam que “[...] quando há interação entre o conhecimento explícito e conhecimento tácito [...], surge a inovação". A inovação é um diferencial competitivo buscado pelas organizações, pois garante a permanência e crescimento da organização.

A gestão do conhecimento não envolve apenas a infraestrutura da organização, ao contrário engloba sua missão, visão, objetivos, metas, estratégias, contexto e, principalmente, os sujeitos organizacionais (funcionários, colaboradores e demais envolvidos). Para Nonaka e Takeuchi (1997, p.82), as organizações são resultantes das interações entre os indivíduos, ou seja, são as pessoas que geram conhecimento de modo individual e, caso não seja realizada nenhuma ação em relação a este conhecimento, o conhecimento individual não será socializado ao coletivo organizacional.

Nessa perspectiva, há a necessidade de os gestores se preocuparem com o conhecimento individual (micro), de modo a compartilhá-lo ao ambiente macro da organização. Nesse intuito, Nonaka e Takeuchi (1997, p.82) criaram o Processo SECI, cuja denominação se refere as iniciais das palavras: socialização, externalização, combinação e internalização. Segundo estes autores, o Processo SECI ocorre em espiral, em que o conhecimento tácito de um indivíduo socializado a outro indivíduo, muitas vezes pode ocorrer apenas no âmbito da observação; em outra etapa da espiral, o conhecimento é externalizado para um grupo de indivíduos como, por exemplo, em uma reunião; a combinação propicia que o conhecimento de um indivíduo seja compartilhado a um coletivo organizacional; e a internalização que propicia que o sujeito organizacional se aproprie do conhecimento socializado no ambiente organizacional e possa gerar 'novo' conhecimento. 
Figura 1: Modelo SECI
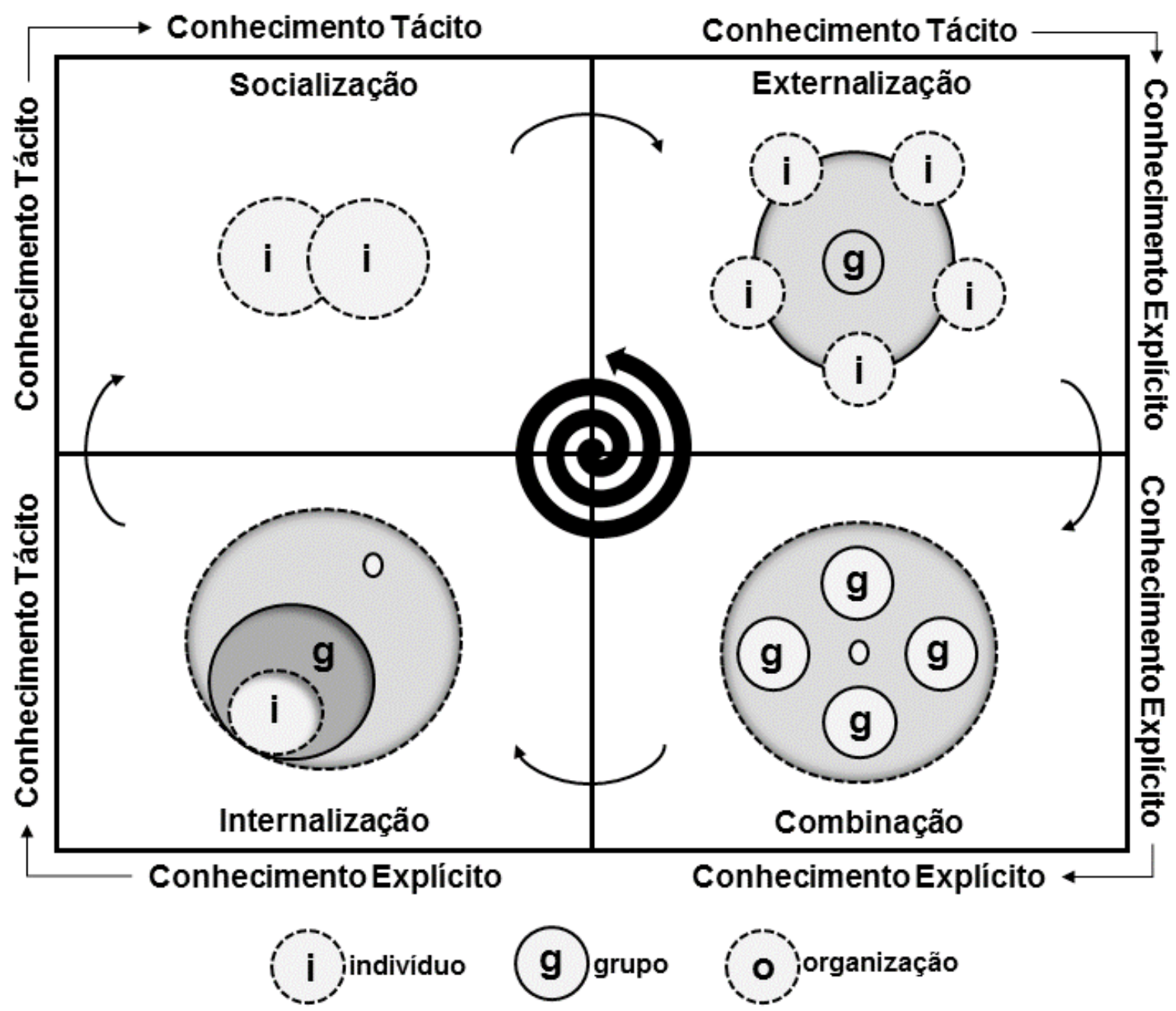

Fonte: Nonaka e Takeuchi - 1997

O Processo SECI enfoca as seguintes possibilidades de conhecimento: socialização: indivíduo para indivíduo; externalização: indivíduo para grupo; combinação: grupo para organização; e internalização: organização para indivíduo. Em todas as abordagens observa-se que a interação entre os pilares indivíduo, grupo e organização demonstram ser a base para a construção de conhecimento.

Independentemente do processo apresentado, evidencia-se que a gestão do conhecimento visa propiciar "[...] o contato apropriado para [a] facilitação das atividades em grupo e para criação e acúmulo de conhecimento em nível individual" (NONAKA; TAKEUCHI, 1997, p.83).

Algumas condições promovem a espiral do conhecimento, são elas: intenção; autonomia; flutuação; caos criativo; redundância e variedade de requisitos (NONAKA; TAKEUCHI, 1997), certamente há outras condições que de algum modo vão ser determinantes para promoverem a espiral do conhecimento e estas são relacionadas a cada tipo de ambiente organizacional.

A GC tem sido explorada em diversos trabalhos como, por exemplo, o de Shuelter e Coelho (2010) que sistematizaram algumas visões e conceituações (Quadro 1). 
Quadro 1: Visão e conceituação da GC

\begin{tabular}{|l|l|}
\hline Autor(es) & \multicolumn{1}{c|}{ Visão - Conceituação } \\
\hline Nonaka e Takeuchi (1997) & $\begin{array}{l}\text { Traz em linhas gerais que a gestão do conhecimento é como um processo, } \\
\text { pelo qual as organizações buscam novas formas de criar e expandir o } \\
\text { conhecimento. }\end{array}$ \\
\hline $\begin{array}{l}\text { Charrapo } \\
(1998)\end{array}$ & $\begin{array}{l}\text { A gestão do conhecimento é como uma metodologia de gerenciamento } \\
\text { que se preocupar com as estratégias para alcançar a inteligência } \\
\text { competitiva. }\end{array}$ \\
\hline Davenport e Prusak (1998) & $\begin{array}{l}\text { Gestão do conhecimento é um conjunto de ações que procura identificar, } \\
\text { capturar, gerenciar e compartilhar as informações da organização. }\end{array}$ \\
\hline $\begin{array}{l}\text { Sveiby } \\
(1998)\end{array}$ & $\begin{array}{l}\text { A gestão do conhecimento é a arte e processo de criar valor, a partir dos } \\
\text { ativos intangíveis da organização }\end{array}$ \\
\hline $\begin{array}{l}\text { Teixeira Filho } \\
(2000)\end{array}$ & $\begin{array}{l}\text { A gestão do conhecimento é uma nova área da união entre a tecnologia } \\
\text { de informação e administração, um campo novo entre a estratégia, a } \\
\text { cultura e os sistemas de informação de uma organização. }\end{array}$ \\
\hline $\begin{array}{l}\text { Angeloni } \\
(2002)\end{array}$ & $\begin{array}{l}\text { Gestão do conhecimento é a criação, disseminação e utilização do } \\
\text { conhecimento, a partir de um conjunto de processos organizacionais. }\end{array}$ \\
\hline $\begin{array}{l}\text { Sullivan } \\
(2005)\end{array}$ & $\begin{array}{l}\text { A gestão do conhecimento é o núcleo de organização de ativos intangíveis } \\
\text { que interfere positivamente o desempenho de uma empresa. }\end{array}$ \\
\hline
\end{tabular}

Fonte: Adaptado de Shuelter e Coelho - 2010

Embora com algumas diferenças, notase a clara presença do elemento 'conhecimento humano', enquanto ativo intangível organizacional, e a necessidade de ações que envolvam a busca do uso consciente e qualitativo deste ativo.

Um dos aspectos que a GC usa como base para sua aplicação são as análises dos FCS. Esses fatores englobam "[...] áreas críticas de planejamento e de ações gerenciais [...]. Em termos de GC, eles podem ser vistos como atividades e práticas que devem ser abordadas, a fim de assegurar o sucesso de sua implementação". (SARAF et al., 1989 apud WONG, 2005, p.262, tradução nossa).

Aliado aos fatores estratégicos, os FCS também são identificados como "[...] o estudo, mapeamento e compreensão dos Fatores Críticos de Sucesso na implementação do processo de GC nas organizações, o que exige uma avaliação mais sistemática e deliberada" (GNECCO JUNIOR et al., 2010, p.57).

Os fatores divergem de acordo com sua aplicação, pois devem ser adaptados às realidades interna e externa da organização, como área de atuação, contexto de mercado, tamanho e abrangência etc. Independente dessas discrepâncias, costumam se concentrar em aspectos de liderança; tecnologia e suportes adequados; pessoas (comprometimento e capacitação); processos (envolvem aspectos de inclusão da GC nos processos da organização); comunicação (traz a necessidade de clareza e padronizações, entre outros) (DAMIAN, 2016). Em todos os aspectos mencionados observa-se a necessidade de se trabalhar fortemente com a cultura organizacional em suas diferentes vertentes.

\section{I Conhecimento}

O conhecimento humano refere-se a um processo extremamente complexo. Segundo Morin (1999, p.26) o ato de conhecimento, ao mesmo tempo biológico, cerebral, espiritual, lógico, linguístico, cultural, social, histórico, faz com que o conhecimento não possa ser dissociado da vida humana e da relação social.

Como evidenciado pelo autor supracitado, inúmeros aspectos estão envolvidos no que denominamos de 'conhecimento humano', e para 
que as organizações possam explorar tal ativo para se obter uma eficiente GC, não é possível desconsiderar tal complexidade.

É possível adotar uma 'falsa' compreensão dessa complexidade, quando se trabalha a GC sem ter a real compreensão quanto à importância das pessoas envolvidas no processo. Sem se ater a isso, seguir modelos ou padrões/indicadores de GC certamente será difícil obter resultados satisfatórios, não por falha do modelo ou dos padrões/indicadores, mas por não compreender a importância do indivíduo no processo com um todo.

Morin (2010) discorre sobre os diferentes olhares que se pode ter sobre um sistema complexo:

\begin{abstract}
À primeira vista, o céu estrelado impressiona por sua desordem: um amontoado de estrelas, dispersas ao acaso. Mas, ao olhar mais atento, aparece a ordem cósmica, imperturbável - cada noite, aparentemente desde sempre e para sempre, o mesmo céu estrelado, cada estrela no seu lugar, cada planeta realizando seu ciclo impecável. Mas vem um terceiro olhar: vem pela injeção de nova e formidável desordem nessa ordem; vemos um universo em expansão, em dispersão, as estrelas nascem, explodem, morrem (MORIN, 2010, p.195).
\end{abstract}

Nessa perspectiva, questiona-se se a GC está preocupada com o segundo ou terceiro olhar expostos por Morin? Dificilmente um processo de GC se ateria apenas ao primeiro olhar, uma vez que a preocupação com esse ativo intangível já demonstra que a organização tem clareza quanto a complexidade do ambiente, ou seja, percebe que a organização é um organismo vivo. No entanto, é possível que as organizações se percam entre os segundo e terceiro olhar, e esse aspecto pode ser identificado nos inúmeros casos em que a GC não obteve o resultado esperado para o qual foi implantada.

O entendimento da organização acerca do processo de conhecimento e de como ele pode ser trabalhado organizacionalmente é primordial para que realmente haja uma valorização do potencial criativo dos sujeitos organizacionais, além disso, é fundamental estabelecer um eixo para a aplicação da GC. Nesse sentido, Belluzzo (2007) destaca:
$\mathrm{Na}$ atual economia, o único paradigma permanente é a mudança. Entretanto, as pessoas constituem o primeiro elemento da mudança e precisam saber a sua razão. É importante que estejam informadas sobre as condições e ambiência do seu desempenho na mudança (BELLUZZO, 2007, p. I0).

Assumir que é necessário que se invista no capital humano envolve a conscientização dos próprios protagonistas, ou seja, os sujeitos organizacionais necessitam perceber sua importância no processo, uma vez que é a partir de o desenvolvimento dessa consciência que poderão buscar as competências necessárias para lidarem com a informação e o próprio conhecimento.

\section{COMPETÊNCIA INFORMAÇÃO (COINFO) \\ EM}

A CoInfo surge em 1974, em meio ao impacto das Tecnologias de Informação e Comunicação (TIC), cujo objetivo era desenvolver habilidades para o uso de bases de dados eletrônicas. Em 1976, assume um sentido mais amplo, voltado para decisões e responsabilidade social (HAMELINK; OENS apud CAMPELLO, 2003).

Com o passar dos anos o conceito foi sendo revisto, ampliado e adequado a realidades e contextos relacionados ao desenvolvimento da Ciência e tecnologia. Atualmente, vêmse intensificando seu papel junto ao contexto das redes, evidenciando o compartilhamento de informação e conhecimento como uma competência essencial para o processo de construção de conhecimento.

Para Fleury e Fleury (2000, p.17): “Competência é um saber agir responsável e reconhecido, o que implica em mobilizar, integrar, transferir conhecimento, recursos, habilidades que agreguem valor à organização e valor social ao indivíduo".

Belluzzo (2007, p.34) ressalta que a competência é composta de duas dimensões: “[...] um domínio de saberes e habilidades de diversas naturezas que permite a intervenção prática na realidade, [...] uma visão crítica do alcance das ações e o compromisso com as necessidades mais concretas que emergem e caracterizam o atual contexto social". 
Os autores supracitados compreendem a CoInfo em uma perspectiva ativa (expressa em ações) e que envolvem também, aspectos sociais. Um exemplo prático de desenvolvimento/ aprimoramento da CoInfo são propostas de educação continuada, conforme exposto por Delors (1998, p.104-105):

[...] o progresso científico e tecnológico e a transformação dos processos de produção resultante da busca de uma maior competitividade fazem com que os saberes e as competências adquiridos, na formação inicial, tornemse, rapidamente, obsoletos e exijam - desenvolvimento da formação profissional permanente. Esta dá resposta, em larga medida, a uma exigência de ordem econômica e faz com que a empresa se dote das competências necessárias para manter o nível de emprego e reforçar a sua competitividade. Fornece, por outro lado, às pessoas, ocasião de atualizarem os seus conhecimentos e possibilidades de promoção.

Mas essa necessidade baseada em progressos científicos e na transformação dos processos de produção também se estende:

Deve fazer com que cada indivíduo saiba conduzir o seu destino, num mundo onde a rapidez das mudanças se conjuga com o fenômeno da globalização para modificar a relação que homens e mulheres mantêm com o espaço e o tempo. As alterações que afetam a natureza do emprego, ainda circunscritas a uma parte do mundo, vão, com certeza, generalizar-se e levar a uma reorganização dos ritmos de vida. A educação ao longo de toda a vida tornase assim, para nós, o meio de chegar a um equilíbrio mais perfeito entre trabalho e aprendizagem bem como ao exercício de uma cidadania ativa (DELORS, 1998, p. I05).

Como destacado por Delors (1998), a aprendizagem ao longo da vida ou educação continuada, atinge patamares sociais que ampliam a cidadania.

A aplicação de tal conceito, porém, se constitui um desafio. Em novo relatório à Unesco, doze anos mais tarde, o autor supracitado ressalta a necessidade de impor tal conceito, destacando seus benefícios em um contexto de "[...] inadequação entre a oferta e a demanda de emprego" em países subdesenvolvidos:

[...] é imperativo impor o conceito de educação ao longo da vida com suas vantagens de flexibilidade, diversidade e acessibilidade no tempo e no espaço. É a ideia de educação permanente que deve ser, simultaneamente, reconsiderada e ampliada; com efeito, além das necessárias adaptações relacionadas com as mudanças da vida profissional, ela deve ser uma construção contínua da pessoa, de seu saber e de suas aptidões, assim como de sua capacidade para julgar e agir. Ela deve permitir que cada um venha a tomar consciência de si próprio e de seu meio ambiente, sem deixar de desempenhar sua função na atividade profissional e nas estruturas sociais (DELORS, 20I0, p.I2).

Benito Morales (2000) apresenta a CoInfo como um processo integrado de competências de natureza variada que representam a maneira com que uma pessoa busca, recupera, organiza, seleciona, avalia e usa informações sob uma perspectiva de sete dimensões (Quadro 2) 
Quadro 2: Dimensões da CoInfo sob a ótica de Félix Benito Morales

\begin{tabular}{|c|c|}
\hline Dimensão & Competência \\
\hline Instrumental & $\begin{array}{l}\text { Capacidade de compreender e usar as ferramentas conceituais e } \\
\text { práticas das TIC, incluindo-se software, hardware e multimídia, que são } \\
\text { relevantes à educação e às áreas pessoais e profissionais. Isto pode } \\
\text { ser entendido como incluir as aplicações básicas dos computadores } \\
\text { e redes, tanto quanto conceitos sobre algoritmos, estrutura de dados, } \\
\text { protocolos e arquiteturas de redes. }\end{array}$ \\
\hline Recursos & $\begin{array}{l}\text { Habilidades para compreender a forma, o formato, os métodos de } \\
\text { localização e acesso aos recursos informacionais, especialmente } \\
\text { aqueles de redes expandidos diariamente. Isso é igual à concepção } \\
\text { dos bibliotecários e incluem conceitos de classificação, indexação e } \\
\text { organização desses recursos. }\end{array}$ \\
\hline Socioestrutural / Redes & $\begin{array}{l}\text { Conhecer como a informação é socialmente situada e produzida. } \\
\text { Isto significa saber acerca de como a informação está se ajustando à } \\
\text { vida das pessoas ou dos grupos sociais: instituições e redes sociais } \\
\text { e de conhecimento - universidades, bibliotecas, comunidades de } \\
\text { pesquisadores, corporações, agências governamentais, grupos } \\
\text { comunitários - que criam e organizam informação e conhecimento; e } \\
\text { os processos sociais através dos quais é gerada - tais como a trajetória } \\
\text { de artigos científicos, as relações entre uma listserv e um grupo de } \\
\text { interesses compartilhados, ou a audiência assistida por uma biblioteca } \\
\text { especializada ou uma página web. }\end{array}$ \\
\hline Editorial & $\begin{array}{l}\text { Habilidade para dar forma e publicar eletronicamente pesquisas e } \\
\text { ideias, em formatos impressos e multimídia. A redação está sempre } \\
\text { apoiada em instrumentos e audiência, devendo se nortear por } \\
\text { princípios de comunicação produtiva. }\end{array}$ \\
\hline Tecnologias & $\begin{array}{l}\text { Habilidade para se adaptar continuamente às tecnologias emergentes, } \\
\text { para compreender, avaliar e fazer uso das contínuas inovações das } \\
\text { TIC, principalmente para tomar decisões inteligentes. Claramente } \\
\text { isto inclui a compreensão do contexto humano, organizativo e social } \\
\text { das tecnologias tanto quanto os critérios para a sua avaliação. }\end{array}$ \\
\hline Crítica & $\begin{array}{l}\text { Habilidade para avaliar criticamente as forças, fraquezas, intelectuais, } \\
\text { humanas e sociais, os limites e as potencialidades, os benefícios e os } \\
\text { custos das TIC. Para tanto, é preciso incluir diferentes perspectivas } \\
\text { nessa dimensão: histórica, filosófica, sociopolítica e cultural. }\end{array}$ \\
\hline
\end{tabular}

Fonte: Adaptado de Benito Morales - 2000, p.38-39 apud Belluzzo - 2007, p.46-47

Inf. \& Soc.:Est., João Pessoa, v.28, n.1, p. 257-267, jan./abr. 2018 
O autor também abrange dimensões pessoais e sociais em suas dimensões, com destaque para inclusão frequente do impacto das TIC, e por trazer na última dimensão (crítica) a necessidade das perspectivas histórica, filosófica, sociopolítica e cultural.
Com base em padrões internacionais e ciente da realidade nacional, Belluzzo (2007, p.95-103) apresenta cinco padrões para o desenvolvimento/aprimoramento da CoInfo, que podem ser utilizados para avaliar e definir o perfil da CoInfo (Figura 2):

Figura 2: Padrões para o desenvolvimento/aprimoramento da CoInfo

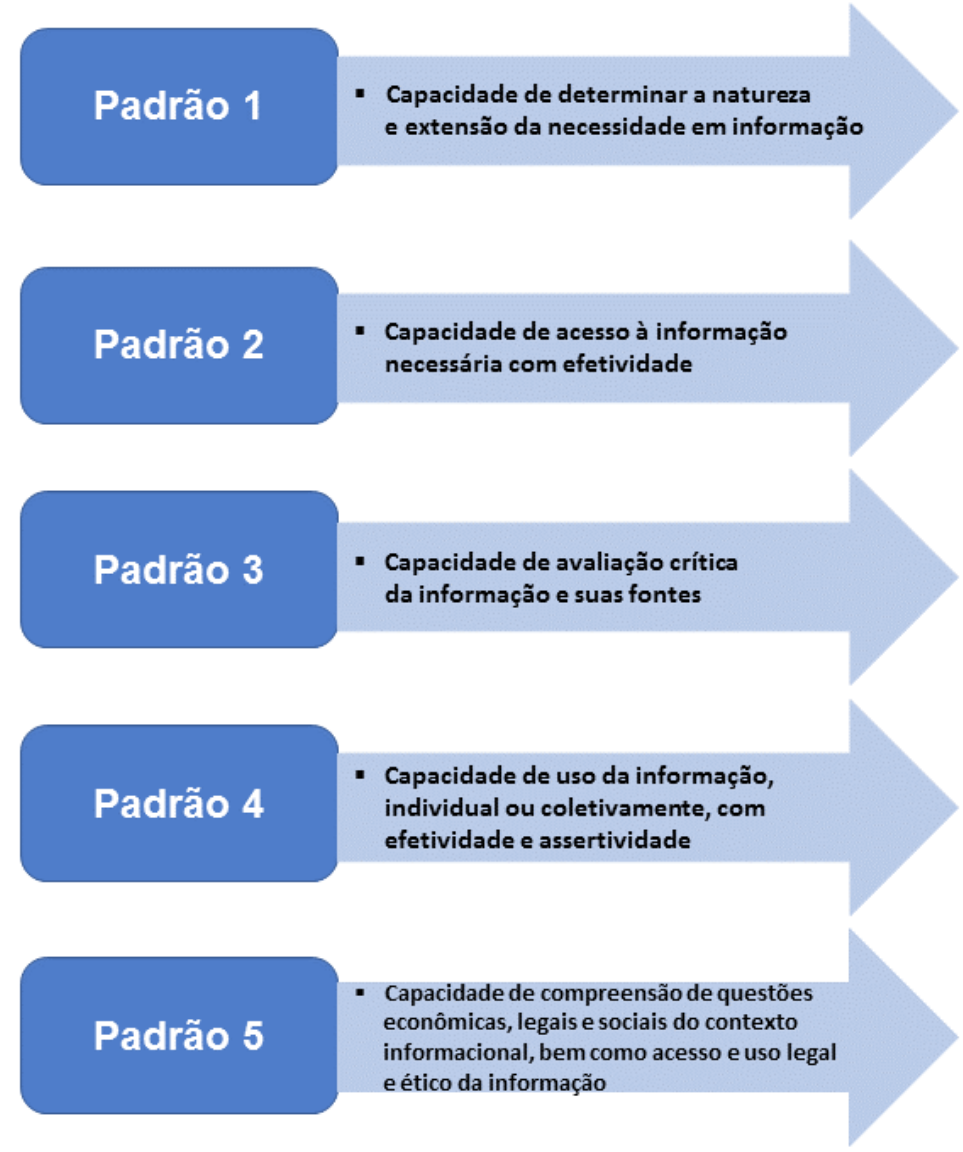

Fonte: Adaptada de Belluzzo - 2007.

Os padrões englobam as competências, habilidades, capacidades e atitudes necessárias para a busca, recuperação, seleção, avaliação e uso efetivo, eficaz e crítico da informação. Partindo-se do primeiro padrão em que se traduz a premência de reconhecer a necessidade informacional, ampliando sua complexidade até o quinto padrão, que abarca as questões éticas e legais, demonstrando se inserir em um contexto macro e se configurando em um processo cíclico e holístico de apreensão, articulação, compreensão e reflexão da informação para atribuição de significado aos fatos e problemas para a intervenção prática na realidade.

\section{RESULTADOS}

A partir da análise da inter-relação entre os principais elementos que compõem os FCS e os principais destaques dos padrões de desenvolvimento/aprimoramento da CoInfo é possível estabelecer as convergências entre eles (Figura 3): 
Figura 3: Inter-relação entre FCS e padrões de desenvolvimento/aprimoramento da CoInfo

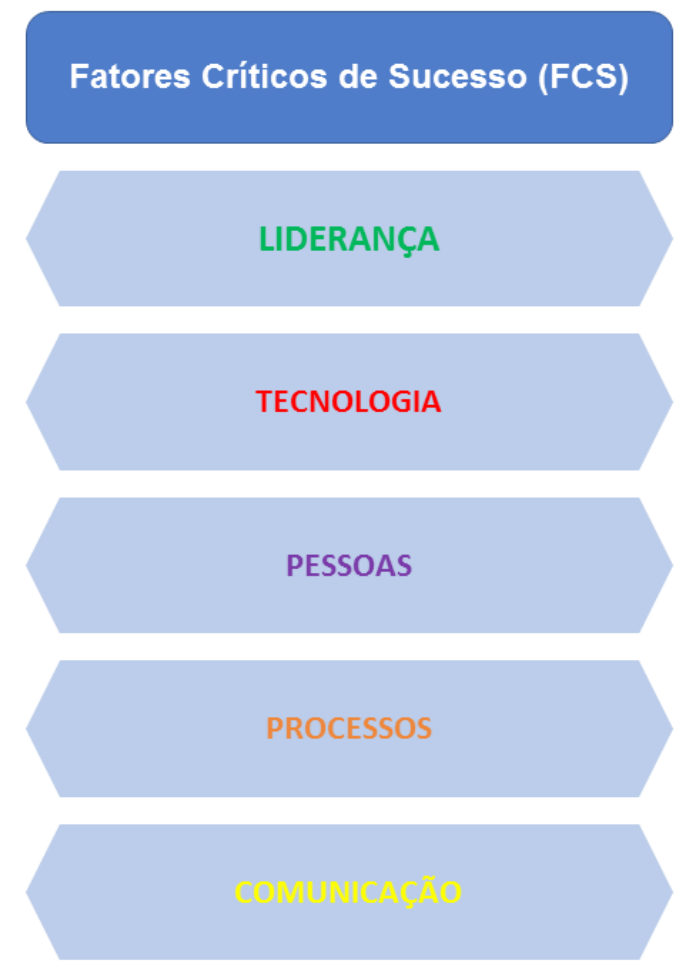

Fonte: Elaboração própria - 2016

É possível notar similaridades quanto à natureza dos aspectos: mesmo no que tange a aspectos tecnológicos, no âmbito da GC não é possível se dissociar do foco humano contextual. Os FCS são frutos de conflitos entre humanos e são solucionados pelos mesmos. Os padrões apresentados possuem natureza relacionada ao acesso à informação de modo inteligente, crítico, reflexivo e criativo.

Os FCS expostos podem ser solucionados se o conhecimento dos envolvidos forem ampliados no âmbito da GC, cujo enfoque é especificamente a valorização e uso inteligente do fator conhecimento humano.

Tendo como exemplo o primeiro FCS descrito (liderança), é possível relacionar: quando há a necessidade de apoio da equipe de liderança para que a GC seja adequadamente aplicada à organização é necessário que os sujeitos organizacionais sejam informados e capacitados para que conheçam a abrangência e os impactos que a aplicação da GC pode

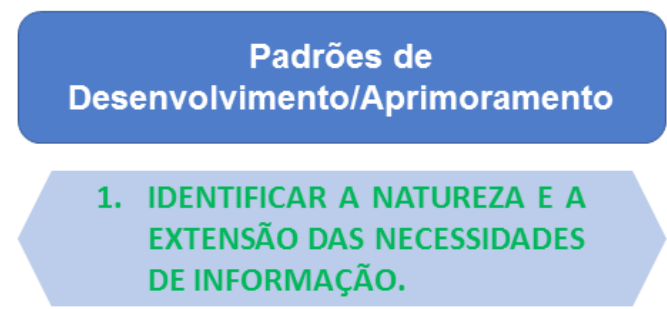

2. ACESO À INFORMAÇÃO COM EFETIVIDADE.

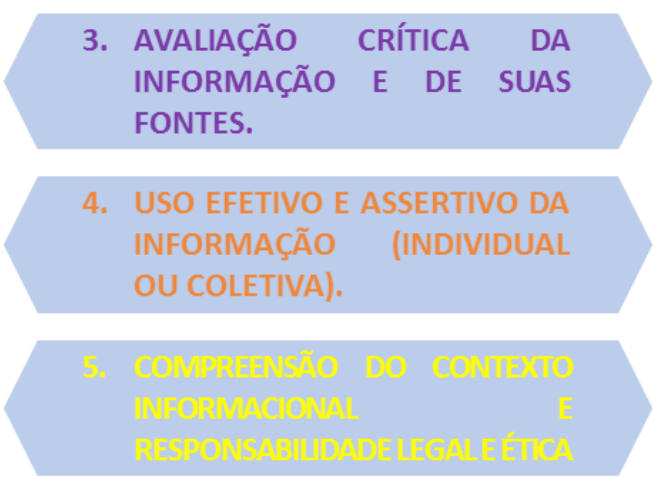

gerar na organização. Além disso, tenham plena compreensão da necessidade desse processo estar alinhado à missão, visão, objetivos e metas organizacionais, bem como sejam capacitados para resolverem possíveis conflitos que possam ocorrer, assumindo seu papel de apoio a todo o processo. Para tanto, o sujeito organizacional precisa ter competências adequadas desenvolvidas para absorver todas essas informações, bem como saber quais outras informações pode precisar durante o processo, e como encontrá-las efetivamente e, ainda, estar ciente das responsabilidades que o acesso e uso dessas informações acarretam.

\section{CONSIDERAÇÕES FINAIS}

Só é possível ampliar conhecimento com a apropriação da informação por um sujeito cognoscente. Por sua vez, para a apropriação da informação no âmbito da GC o sujeito 
organizacional, seja gestor, funcionário ou colaborador, precisa ser capacitado para isso, principalmente pelas características complexas envolvidas, porquanto trabalha com as nuances do intangível. Como ressalta Oliveira (2015, p.20): “[...] o estar no mundo, por si só, não apresenta a resposta da construção do conhecimento, há a real necessidade de imersão e familiaridade com suas peculiaridades e expressões de sociedade".

Essa visão completa do 'sujeito', da necessidade de imersão em contraposição ao estar, e o respeito à complexidade no que tange a sua construção de conhecimento, aliada a perspectivas de uma GC consciente bem como dos FCS, estabelece a base perfeita para que processos de desenvolvimento da CoInfo sejam aplicados em organizações de qualquer natureza, delineando o desenvolvimento consciente dos envolvidos.

É possível concluir que essas similaridades podem ser mais amplamente abordadas, resultando inclusive em padrões específicos para cada um dos FCS.

Artigo recebido em 25/0I/20I7 e aceito para publicação em I8/0I/20I8

\section{INFORMATION LITERACY IN SUPPORT OF KNOWLEDGE MANAGEMENT}

\section{ABSTRACT}

In a context of increasing importance of information and knowledge, the 2 Ist Century has been evidenced as a reformulator of institutional policies, enhancing human capital to generate innovation and gain competitive advantage. However, the initiatives aimed at the application of a management that, really can work the human capital in its potentiality are few. Critical success factors are relevant elements that are part of knowledge management and, as such, should be strongly monitored. Critical success factors can range from communication, technology, people, processes, to leadership. In this scenario, information literacy emphasizes the perspective that the organizational individual is able to use information critically, reflexively, creatively, autonomously and ethically in different situations. The use of consistent and reliable information for the construction of organizational knowledge is essential, however, it is questioned: are organizational individuals competent in the use of information? Organizational individuals know their own informational needs? Based on a bibliographical review, this article emphasizes the need to develop knowledge management aligned with information literacy. In this sense, the similarities between the information literacy and critical success factors were identified, in order to propose contributions to the knowledge management to obtain effective effectiveness. As a result, presents the main critical success factors interrelated to the main patterns of development/ improvement of information literacy, highlighting the similarities, as well as exposing the need to value the relevant use of information for the generation of knowledge.

Keywords: Knowledge Management. Information Literacy. Critical Success Factors. Information Literacy Patterns.

\section{REFERÊNCIAS}

BELLUZZO, R. C. B. Construção de mapas: desenvolvendo competências em informação e comunicação. 2. ed. Bauru: Cá Entre Nós, 2007.

CAMPELLO, B. S. O movimento da competência informacional: uma perspectiva para o letramento informacional. Ciência da Informação, Brasília, v.32, n.3, p.28-37, set./dez. 2003. Disponível em: <http://revista.ibict.br/ ciinf/article/view/986/1028>. Acesso em: 20 jan. 2017.

DAMIAN, I. P. M. Fatores críticos de sucesso para a gestão do conhecimento. Marília, 2016. 26 slides. Apresentação em Power-Point.

DELORS, J. Educação: um tesouro a descobrir. Relatório para a Unesco da Comissão Interna sobre Educação para o século XXI. São Paulo: Cortez; UNESCO, 1998. 288p. Disponível em: <http://www.profdoni.pro.br/home/images/ 
sampledata/2015/livros/O_PODER_DO_ AGORA_Eckhart_Tolle.pdf>. Acesso em: 20 jan. 2017.

(Org.). Educação: um tesouro a descobrir. Relatório para a Unesco da Comissão Interna sobre Educação para o século XXI: destaques. Brasília: UNESCO, 2010. 43p. Disponível em: <http://unesdoc.unesco.org/ images/0010/001095/109590por.pdf $>$. Acesso em20 jan. 2017.

FLEURY, A.; FLEURY, M. T. L. Estratégias empresariais e formação de competências. São Paulo: Atlas, 2000.

GNECCO JÚNIOR, L. et al. Gestão do conhecimento: fatores críticos de sucesso. REUNA, Belo Horizonte, v.15, n.1, p.47-64, jan./ abr. 2010. Disponível em: <http://revistas.una. br/index.php/reuna/article/view/302/422>. Acesso em: 20 jan. 2017.

MORIN, E. Ciência com consciência. 2.ed. Rio de Janeiro: Bertrand Russel, 2010.

O método 3: o conhecimento do conhecimento. Porto Alegre: Sulina, 1999.

NONAKA, I.; TAKEUCHI, H. Criação de conhecimento na empresa: como as empresas japonesas geram a dinâmica da inovação. Rio de Janeiro: Elsevier, 1997.

\section{OLIVEIRA, H. C. C. A mediação em projetos de} incentivo à leitura: a apropriação da informação para construção do conhecimento e do pensamento crítico. 2015. Dissertação (Mestrado) - Programa de Pós-Graduação em Ciência da Informação, Faculdade de Filosofia e Ciências, Universidade Estadual Paulista (Unesp), Marília, 2015.

SCHUELTER, G.; COELHO, C. C. S. R. Gestão do conhecimento nos sistemas de educação a distância: técnicas e ferramentas para melhorar o processo de produção. In: CONGRESSO INTERNACIONAL DE EDUCAÇÃO A DISTÂNCIA, 16., Foz do Iguaçu, 2010. Anais eletrônicos... Foz do Iguaçu: ABED, 2010. Disponível em: <http://www.abed.org.br/ congresso2010/cd/152010184116.pdf>. Acesso em: 20 jan. 2017.

WONG, Y. K. Critical success factors for implementing knowledge management in small and medium enterprises. Industrial Management \& Data Systems, v.105, n.3, p.261279, 2005. 
